\title{
Front Matter: Volume 8082
}

, "Front Matter: Volume 8082," Proc. SPIE 8082, Optical Measurement Systems for Industrial Inspection VII, 808201 (23 May 2011); doi:

10.1117/12.898995

SPIE. Event: SPIE Optical Metrology, 2011, Munich, Germany 


\section{PROCEEDINGS OF SPIE}

\section{Optical Measurement Systems for Industrial Inspection VII}

Peter H. Lehmann

Wolfgang Osten

Kay Gastinger

Editors

23-26 May 2011

Munich, Germany

Sponsored and Published by

SPIE

Volume 8082 
The papers included in this volume were part of the technical conference cited on the cover and title page. Papers were selected and subject to review by the editors and conference program committee. Some conference presentations may not be available for publication. The papers published in these proceedings reflect the work and thoughts of the authors and are published herein as submitted. The publisher is not responsible for the validity of the information or for any outcomes resulting from reliance thereon.

Please use the following format to cite material from this book:

Author(s), "Title of Paper," in Optical Measurement Systems for Industrial Inspection VII, edited by Peter H. Lehmann, Wolfgang Osten, Kay Gastinger, Proceedings of SPIE Vol. 8082 (SPIE, Bellingham, WA, 2011) Article CID Number.

ISSN 0277-786X

ISBN 9780819486783

Published by

SPIE

P.O. Box 10, Bellingham, Washington 98227-0010 USA

Telephone +1 3606763290 (Pacific Time) · Fax +13606471445

SPIE.org

Copyright (C) 2011, Society of Photo-Optical Instrumentation Engineers

Copying of material in this book for internal or personal use, or for the internal or personal use of specific clients, beyond the fair use provisions granted by the U.S. Copyright Law is authorized by SPIE subject to payment of copying fees. The Transactional Reporting Service base fee for this volume is $\$ 18.00$ per article (or portion thereof), which should be paid directly to the Copyright Clearance Center (CCC), 222 Rosewood Drive, Danvers, MA 01923. Payment may also be made electronically through CCC Online at copyright.com. Other copying for republication, resale, advertising or promotion, or any form of systematic or multiple reproduction of any material in this book is prohibited except with permission in writing from the publisher. The CCC fee code is 0277-786X/11/\$18.00.

Printed in the United States of America.

Publication of record for individual papers is online in the SPIE Digital Library.

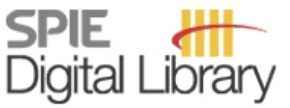

SPIEDigitalLibrary.org

Paper Numbering: Proceedings of SPIE follow an e-First publication model, with papers published first online and then in print and on CD-ROM. Papers are published as they are submitted and meet publication criteria. A unique, consistent, permanent citation identifier (CID) number is assigned to each article at the time of the first publication. Utilization of CIDs allows articles to be fully citable as soon they are published online, and connects the same identifier to all online, print, and electronic versions of the publication. SPIE uses a six-digit CID article numbering system in which:

- The first four digits correspond to the SPIE volume number.

- The last two digits indicate publication order within the volume using a Base 36 numbering system employing both numerals and letters. These two-number sets start with $00,01,02,03,04$, $05,06,07,08,09,0 A, 0 B \ldots 0 Z$, followed by 10-1Z, 20-2Z, etc.

The CID number appears on each page of the manuscript. The complete citation is used on the first page, and an abbreviated version on subsequent pages. Numbers in the index correspond to the last two digits of the six-digit CID number. 


\title{
Contents
}

\section{Part One}

\author{
xix Conference Committee \\ xxi Introduction
}

\section{SESSION 1 MULTISENSOR APPROACHES}

808202 Assistant systems for efficient multiscale measurement and inspection [8082-01]

A. Burla, T. Haist, W. Lyda, M. H. Aissa, W. Osten, Univ. Stuttgart (Germany)

808203 Multisensor technology based on a laser focus probe for nanomeasuring applications over large areas [8082-02]

E. Manske, G. Jäger, T. Hausotte, T. Machleidt, Ilmenau Univ. of Technology (Germany)

808204 Conceptual consideration for the process integration of optical sensors [8082-03]

D. Fleischle, W. Lyda, F. Mauch, W. Osten, Univ. Stuttgart (Germany)

\section{SESSION 2 DIGITAL HOLOGRAPHY}

808205 Some figures of merit so as to compare digital Fresnel holography and speckle interferometry (Invited Paper) [8082-04]

P. Slangen, Ecole des Mines d'Alès (France); M. Karray, LAUM, CNRS, Univ. du Maine (France); P. Picart, LAUM, CNRS, Univ. du Maine (France) and École Nationale Supérieure d'Ingénieurs du Mans (France)

808206 Reference wave adaptation in digital lensless Fourier holography by means of a spatial light modulator [8082-05]

T. Meeser, C. Falldorf, C. von Kopylow, R. B. Bergmann, Bremer Institut für angewandte Strahltechnik GmbH (Germany)

808207 Self interference digital holographic microscopy approach for inspection of technical and biological phase specimens [8082-06]

B. Kemper, F. Schlichthaber, A. Vollmer, S. Ketelhut, S. Przibilla, G. von Bally, Univ. of Muenster (Germany)

808208 Stokes holography for recording and reconstructing objects using polarization fringes [8082-07]

R. K. Singh, D. N. Naik, H. Itou, Y. Miyamoto, M. Takeda, The Univ. of Electro-Communications (Japan)

808209 An algorithm for the estimation of the in-focus distance for speckle holograms [8082-08] P. Memmolo, Istituto Nazionale di Ottica, CNR (Italy) and Univ. degli Studi di Napoli Federico II (Italy); C. Distante, M. Paturzo, A. Finizio, P. Ferraro, Istituto Nazionale di Ottica, CNR (Italy); B. Javidi, Univ. of Connecticut (United States) 
8082 OA Synthetic aperture engineering for super-resolved microscopy in digital lensless Fourier holography [8082-09]

V. Micó, Univ. de València (Spain); L. Granero, AIDO, Instituto Tecnológico de Óptica, Color e Imagen (Spain); Z. Zalevsky, Bar-Ilan Univ. (Israel); J. García, Univ. de València (Spain)

8082 OB Dual-wavelength holographic shape measurement with iterative phase unwrapping [8082-11]

S. Rosendahl, P. Bergström, P. Gren, M. Sjödahl, Luleå Univ. of Technology (Sweden)

8082 OC Infrared digital holography for large objects investigation [8082-12]

A. Geltrude, Istituto Nazionale di Ottica, CNR (Italy); M. Locatelli, Istituto Nazionale di Ottica, CNR (Italy) and Univ. di Firenze (Italy); P. Poggi, A. Pelagotti, M. Paturzo, P. Ferraro,

R. Meucci, Istituto Nazionale di Ottica, CNR (Italy)

8082 OD Remote laboratory for digital holographic metrology [8082-13]

M. Wilke, I. Alekseenko, G. Situ, K. Sarker, M. Riedel, G. Pedrini, W. Osten, Univ. Stuttgart (Germany)

8082 OE Simultaneous out-of-plane and in-plane displacements measurement by using digital holography around a hole or indentation [8082-14]

M. R. Viotti, Univ. Federal de Santa Catarina (Brazil); C. Kohler, Univ. Federal de Santa Catarina (Brazil) and Univ. Stuttgart (Germany); A. Albertazzi, Jr., Univ. Federal de Santa Catarina (Brazil)

$80820 G$ Recent advances in the field of super resolved imaging and sensing (Invited Paper) [8082-16]

Z. Zalevsky, Bar-Ilan Univ. (Israel); A. Borkowski, E. Marom, Tel-Aviv Univ. (Israel); B. Javidi, Univ. of Connecticut (United States); Y. Beiderman, Bar-llan Univ. (Israel); V. Micó, J. García, Univ. de València (Spain)

$8082 \mathrm{OH} \quad$ Advanced 2D die placement inspection system for reliable flip chip interconnections based on 3D information of die and substrate by a phase measuring profilometry [8082-17] H.-K. Lee, Koh Young Technology, Inc. (Korea, Republic of); M. Y. Kim, Kyungpook National Univ. (Korea, Republic of)

8082 Ol 3D interconnect metrology in CMS/ITRI [8082-18] Y. S. Ku, D. M. Shyu, W. T. Hsu, P. Y. Chang, Y. C. Chen, H. L. Pang, Industrial Technology Research Institute (Taiwan)

8082 0J Pattern placement metrology using PROVE high precision optics combined with advanced correction algorithms [8082-19]

M. Längle, N. Rosenkranz, D. Seidel, D. Beyer, Carl Zeiss SMS GmbH (Germany)

8082 OK Detection of micro-probe displacement using a Shack-Hartmann wavefront sensor [8082-20]

H. Dierke, C. Schrader, R. Tutsch, Technische Univ. Braunschweig (Germany) 
$8082 \mathrm{OL}$ Optimal phase retrieval from multiple observations with Gaussian noise: augmented Lagrangian algorithm for phase objects [8082-21]

A. Migukin, V. Katkovnik, J. Astola, Tampere Univ. of Technology (Finland)

$80820 \mathrm{M}$ The effect of misalignment in phase retrieval based on a spatial light modulator [8082-22] M. Agour, Bremer Institut für angewandte Strahltechnik GmbH (Germany) and South Valley Univ. (Egypt); C. Falldorf, C. von Kopylow, R. B. Bergmann, Bremer Institut für angewandte Strahltechnik GmbH (Germany)

$80820 \mathrm{~N}$ Quantitative determination of the optical properties of phase objects by using a real-time phase retrieval technique [8082-23]

J. Frank, Cologne Univ. of Applied Sciences (Germany) and Humboldt-Univ. zu Berlin (Germany); G. Wernicke, Humboldt-Univ. zu Berlin (Germany); J. Matrisch, RheinAhrCampus Remagen (Germany); S. Wette, J. Beneke, S. Altmeyer, Cologne Univ. of Applied Sciences (Germany)

808200 Phase extraction in microscopy using tunable defocusing by means of a SLM [8082-24] L. Camacho, V. Micó, Univ. de València (Spain); Z. Zalevsky, Bar-llan Univ. (Israel); J. García, Univ. de València (Spain)

\section{SESSION 6 OPTICAL PROFILOMETRY}

8082 OP Three-dimensional refractive index and thickness distribution of thin film measurements through dynamic multiwavelength interferometry [8082-25]

K. Wu, C.-C. Lee, National Central Univ. (Taiwan)

$80820 Q$ Comparison of fast Fourier transform and convolution in wavelength scanning interferometry [8082-26]

H. Muhamedsalih, X. Jiang, F. Gao, Univ. of Huddersfield (United Kingdom)

8082 OR Absolute surface profilometry of an object with large gaps by means of monochromatic laser interferometry [8082-27]

Z. Liu, K. Uchikawa, Nikon Corp. (Japan); M. Takeda, The Univ. of Electro-Communications (Japan)

8082 OS Structured-illumination microscopy on technical surfaces: 3D metrology with nanometer sensitivity [8082-28]

M. Vogel, Z. Yang, A. Kessel, C. Kranitzky, C. Faber, G. Häusler, Friedrich-Alexander-Univ. Erlangen-Nürnberg (Germany)

\section{SESSION 7 WHITE-LIGHT INTERFEROMETRY}

8082 OT Broad spectral range measurement of chromatic dispersion of polarization modes in holey fibers using spectral interferometry [8082-29]

P. Hlubina, D. Ciprian, Technical Univ. Ostrava (Czech Republic); T. Martynkien, Wroclaw Univ. of Technology (Poland); P. Mergo, Maria Curie-Sklodowska Univ. (Poland);

W. Urbańczyk, Wroclaw Univ. of Technology (Poland) 
8082 OU Inspection of processes during silicon wafer sawing using low coherence interferometry in the near infrared wavelength region [8082-30]

K. Gastinger, Norwegian Univ. of Science and Technology (Norway); L. Johnsen, SINTEF

(Norway); O. Simonsen, A. Aksnes, Norwegian Univ. of Science and Technology (Norway)

$8082 \mathrm{OV}$ Uncertainty of height information in coherence scanning interferometry [8082-31]

J. Seewig, Technische Univ. Kaiserslautern (Germany); T. Böttner, Dyadic Computing

(Germany); D. Broschart, Technische Univ. Kaiserslautern (Germany)

$8082 \mathrm{OW}$ Improvement of lateral resolution and reduction of batwings in vertical scanning white-light interferometry [8082-32]

J. Niehues, P. Lehmann, Univ. of Kassel (Germany)

8082 0X Parallel optical coherence tomography (pOCT) for industrial 3D inspection [8082-33]

P. Lambelet, Heliotis AG (Switzerland)

\section{SESSION 8 HIGH-SPEED TECHNIQUES}

8082 OY High-speed fringe projection for fast 3D inspection [8082-34]

S. Caspar, M. Honegger, S. Rinner, NTB Univ. of Applied Sciences of Technology

(Switzerland); P. Lambelet, Heliotis AG (Switzerland); C. Bach, A. Ettemeyer, NTB Univ. of

Applied Sciences of Technology (Switzerland)

$80820 Z$ Radial expansion measurements of a high-speed rotor using an interferometric array sensor [8082-35]

J. Czarske, P. Günther, F. Dreier, T. Pfister, T. Haupt, W. Hufenbach, Technische Univ. Dresden (Germany)

808210 High-speed, on-line 4D microscopy using continuously scanning white light interferometry with a high-speed camera and real-time FPGA image processing [8082-36]

P. Montgomery, F. Anstotz, J. Montagna, Institut d'Électronique du Solide et des Systèmes, CNRS (France)

808211 3D high-speed profilometer for inspection of micro-manufactured transparent parts [8082-37]

D. M. Ljubicic, B. W. Anthony, Massachusetts Institute of Technology (United States)

808212 Fringe projection based high-speed 3D sensor for real-time measurements [8082-38]

C. Bräuer-Burchardt, A. Breitbarth, P. Kühmstedt, I. Schmidt, M. Heinze, G. Notni, Fraunhofer-

Institut für Angewandte Optik und Feinmechanik (Germany)

\section{SESSION 9 DEFLECTOMETRY, FRINGE PROJECTION}

808213 Alignment methods for ultraprecise deflectometric flatness metrology [8082-39]

G. Ehret, M. Schulz, A. Fitzenreiter, M. Baier, W. Jöckel, M. Stavridis, C. Elster, PhysikalischTechnische Bundesanstalt (Germany) 
808214 Measurement and characterization of cylindrical surfaces by deflectometry applied to ballistic identification [8082-40]

A. V. Fantin, Federal Univ. of Santa Catarina (Brazil); C. Veiga, Photonita Ltd. (Brazil);

A. Albertazzi, Federal Univ. of Santa Catarina (Brazil)

808215 Endoscopic geometry inspection by modular fiber optic sensors with increased depth of focus [8082-41]

C. Ohrt, M. Kästner, E. Reithmeier, Leibniz Univ. Hannover (Germany)

808216 3D measuring in the field of endoscopy [8082-42]

A. Schick, F. Forster, M. Stockmann, Siemens AG (Germany)

808217 3D shape measurement based on color-encoded sinusoidal fringe projection [8082-43]

Q. Zhang, K. Ma, Sichuan Univ. (China)

SESSION 10 STRUCTURED LIGHT TECHNIQUES

808218 New structured light measurement and calibration method for 3D documenting of engineering structures [8082-44]

R. Sitnik, M. Kujawińska, P. M. Błaszczyk, Warsaw Univ. of Technology (Poland)

808219 Fast 3D shape measurements using laser speckle projection [8082-45]

M. Schaffer, M. Große, B. Harendt, R. Kowarschik, Friedrich-Schiller-Univ. Jena (Germany)

$80821 \mathrm{~A}$ Optical measurement and comparison of large free form surfaces through a regular mesh [8082-46]

T. L. Pinto, Univ. Federal de Santa Catarina (Brazil); C. Kohler, Univ. Stuttgart (Germany);

A. Albertazzi, Jr., Univ. Federal de Santa Catarina (Brazil)

8082 1B Accurate calibration of a fringe projection system by considering telecentricity [8082-47]

K. Haskamp, M. Kästner, E. Reithmeier, Leibniz Univ. Hannover (Germany)

\section{SESSION 11 JOINT SESSION I: MEASUREMENTS OF OPTICAL COMPONENTS AND SYSTEMS}

$80821 \mathrm{C}$ Some aspects of error influences in interferometric measurements of optical surface forms (Invited Paper) [8082-48]

M. Schulz, A. Wiegmann, Physikalisch-Technische Bundesanstalt (Germany)

8082 1D Diffractive simultaneous lateral shearing interferometry [8082-49]

V. Nercissian, Friedrich-Alexander-Univ. Erlangen-Nürnberg (Germany); I. Harder, K. Mantel, Max Planck Institute for the Science of Light (Germany); A. Berger, N. Lindlein, Friedrich-

Alexander-Univ. Erlangen-Nürnberg (Germany)

$80821 \mathrm{E}$ Aspherical surface measurement using quadri-wave lateral shearing interferometry [8082-50]

W. Boucher, P. Delage, B. Wattellier, PHASICS S.A. (France)

$8082 \mathrm{lF}$ Advanced studies on the measurement of aspheres and freeform surfaces with the tilted-wave interferometer [8082-51]

E. Garbusi, G. Baer, W. Osten, Univ. Stuttgart (Germany) 
$80821 G \quad$ A subaperture stitching algorithm for aspheric surfaces [8082-52]

P.-C. Lin, Y.-C. Chen, National Central Univ. (Taiwan); C.-M. Lee, California State Univ., Long

Beach (United States); C.-W. Liang, National Central Univ. (Taiwan)

\section{SESSION 12 JOINT SESSION II: MEASUREMENT OF OPTICAL COMPONENTS AND SYSTEMS}

$808211 \quad$ Axicon metrology using line density computer-generated holograms [8082-54]

J. Ma, Univ. Stuttgart (Germany) and Nanjing Univ. of Science \& Technology (China):

C. Pruss, M. Häfner, Univ. Stuttgart (Germany); R. Zhu, Z. Gao, Nanjing Univ. of Science \&

Technology (China); C. Yuan, W. Osten, Univ. Stuttgart (Germany)

$80821 \mathrm{~J} 3 \mathrm{D}$ profilometry on aspheric and freeform lenses [8082-55]

A. Beutler, Mahr GmbH (Germany)

$80821 \mathrm{~K}$ Measurements of aberrations of aspherical lenses using experimental ray tracing [8082-56]

U. Ceyhan, T. Henning, F. Fleischmann, D. Hilbig, Univ. of Applied Sciences Bremen

(Germany); D. Knipp, Jacobs Univ. (Germany)

$8082 \mathrm{lL}$ Automated alignment of aspheric and freeform surfaces in a non-null test interferometer [8082-57]

G. Baer, E. Garbusi, W. Lyda, C. PruB, W. Osten, Univ. Stuttgart (Germany)

$80821 \mathrm{M}$ Complete characterization of assembled optics with respect to centering error and lens distances [8082-58]

J. Heinisch, P. Langehanenberg, H. Pannhoff, Trioptics GmbH (Germany)

8082 IN Interferometric measurement of profile deviations of large precision mirrors [8082-59]

A. Müller, G. Jäger, E. Manske, Ilmenau Univ. of Technology (Germany)

808210 Measuring amplitude and phase of light emerging from microstructures with HRIM [8082-60]

T. Scharf, M.-S. Kim, H. P. Herzig, Ecole Polytechnique Fédérale de Lausanne (Switzerland)

\section{SESSION 13 3D INTERFEROMETRIC TECHNIQUES}

$80821 Q \quad$ Numerical noise reduction via diffraction for surface profiling interferometry [8082-62]

H. Toba, S. Nakayama, H. Homma, T. Gemma, K. Uchikawa, Nikon Corp. (Japan)

8082 IR Dynamic measurements using a Fizeau interferometer [8082-63]

D. M. Sykora, M. L. Holmes, Zygo Corp. (United States)

8082 is Fringe pattern characterization by OPD analysis in a lateral shearing interferometric profilometer [8082-64]

M. Frade, J. M. Enguita, I. Álvarez, S. Rodríguez-Jiménez, Univ. of Oviedo (Spain)

8082 1T State of polarization mapping using a calibrated interferometric polarimeter [8082-65]

D. N. Naik, R. K. Singh, H. Itou, Y. Miyamoto, M. Takeda, The Univ. of Electro-Communications (Japan) 
$80821 \mathrm{U}$ High resolution speckle interferometry by replacing temporal information with spatial information [8082-66]

Y. Arai, T. Inove, Kansai Univ. (Japan); S. Yokozeki, Jyouko Applied Optics Lab. (Japan)

\section{SESSION 14 INTERFEROMETRIC VIBRATION MEASUREMENTS}

8082 IV SLM-based multipoint vibrometry [8082-67]

T. Haist, Univ. Stuttgart (Germany); A. Tarbeyevskaya, Polytec GmbH (Germany); M. Warber, W. Osten, Univ. Stuttgart (Germany); C. Rembe, M. Ludwig, Polytec GmbH (Germany);

W. Stork, Karlsruhe Institute of Technology (Germany)

8082 IW Adaptive optical head for industrial vibrometry applications [8082-68]

R. Atashkhooei, Univ. Politècnica de Catalunya (Spain); U. Zabit, Univ. de Toulouse (France);

S. Royo, Univ. Politècnica de Catalunya (Spain); T. Bosch, F. Bony, Univ. de Toulouse (France)

$80821 \mathrm{X}$ Vibration amplitude recovery from time averaged interferograms using the directional spatial carrier phase shifting method [8082-69]

A. Styk, M. Brzeziński, Institute of Micromechanics and Photonics (Poland)

$80821 \mathrm{Y}$ Application of wavelet transform and image morphology in processing vibration speckle interferogram for automatic analysis [8082-70]

R. Kumar, D. P. Jena, Sant Longowal Institute of Engineering and Technology (India);

C. Shakher, Indian Institute of Technology Delhi (India)

\section{SESSION 15 PARTICLE MEASUREMENT}

808212 High-sensitivity low-coherence dynamic light scattering and particle sizing for nanoparticles [8082-71]

K. Ishii, The Graduate School for the Creation of New Photonics Industries (Japan);

S. Nakamura, Y. Sato, FUJIFILM Corp. (Japan)

808220 Novel non-contact optical characterisation methods of polymeric nanocomposite structures based on their particle loading and dispersion profile [8082-72]

T. Koukoulas, W. R. Broughton, M. Tedaldi, P. D. Theobald, National Physical Lab. (United Kingdom)

808221 Mueller matrix imaging of nematic textures in colloidal dispersions of Na-fluorohectorite synthetic clay [8082-73]

M. Kildemo, L. M. S. Aas, P. G. Ellingsen, H. Hemmen, E. L. Nilsen, J. O. Fossum, Norwegian Univ. of Science and Technology (Norway) 


\section{Part Two}

\section{SESSION 16 NONDESTRUCTIVE INSPECTION AND PROCESS MONITORING}

808222 3D optical measuring technologies for industrial applications (Invited Paper) [8082-74] Y. Chugui, Technological Design Institute of Scientific Instrument Engineering (Russian Federation), Novosibirsk State Univ. (Russian Federation), and Novosibirsk State Technical Univ. (Russian Federation); A. Verkhogliad, V. Kalikin, P. Zav'yalov, Technological Design Institute of Scientific Instrument Engineering (Russian Federation)

808223 Lockin-interferometric imaging of thermal waves for nondestructive testing [8082-75] P. Menner, G. Busse, Univ. Stuttgart (Germany)

808224 Laser ultrasonics evaluation and testing of coated HTR nuclear fuel [8082-76]

A. Amziane, M. Amari, LPEC, CNRS, Univ. du Maine (France); D. Mounier, LPEC, CNRS, Univ. du Maine (France) and ENSIM (France); J.-M. Breteau, LPEC, CNRS, Univ. du Maine (France); N. Joly, LAUM, CNRS, Univ. du Maine (France) and ENSIM (France); M. Edely, LPEC, CNRS, Univ. du Maine (France); M. Larcher, P. Noiré, ENSIM (France); J. Banchet, D. Tisseur, AREVA (France); V. Gusev, LPEC, CNRS, Univ. du Maine (France)

808225 Laser induced deflection (LID) method for absolute absorption measurements of optical materials and thin films [8082-77]

C. Mühlig, S. Bublitz, W. Paa, Institute of Photonic Technology (Germany)

808226 Reflectometry for TSV etching depth inspection [8082-78]

W.-T. Hsu, Y.-S. Ku, Industrial Technology Research Institute (Taiwan)

808227 Optical characterization of phase gratings written by a UV femtosecond laser in PMMA [8082-79]

S. De Nicola, S. Abdalah, Istituto Nazionale di Ottica Applicata, CNR (Italy); K. Al-Naimee, Istituto Nazionale di Ottica Applicata, CNR (Italy) and The Univ. of Manchester (United Kingdom); A. Geltrude, Istituto Nazionale di Ottica Applicata, CNR (Italy); M. Locatelli, Istituto Nazionale di Ottica Applicata, CNR (Italy) and Univ. di Firenze (Italy); R. Meucci, Istituto Nazionale di Ottica Applicata, CNR (Italy); A. Baum, W. Perrie, P. J. Scully, A. Taranu, The Univ. of Manchester (United Kingdom); F. T. Arecchi, Istituto Nazionale di Ottica Applicata, CNR (Italy) and Univ. di Firenze (Italy)

808228 Development of a FD-OCT for the inline process metrology in laser structuring systems [8082-80]

R. Schmitt, Fraunhofer Institute for Production Technology (Germany) and RWTH Aachen (Germany); G. Mallmann, Fraunhofer Institute for Production Technology (Germany); P. Peterka, Institute of Photonics and Electronics (Czech Republic)

808229 Turning process monitoring using a robust and miniaturized non-incremental interferometric distance sensor [8082-81]

P. Günther, F. Dreier, T. Pfister, J. Czarske, Technische Univ. Dresden (Germany) 
8082 2A Measurement of surface resistivity/conductivity of carbon steel in 5-20ppm of KGR-134 inhibited seawater by holographic interferometry techniques [8082-82]

K. Habib, Kuwait Institute for Scientific Research (Kuwait)

8082 2B Reconstruction of 3D refractive index distribution across the graded index optical fibre using digital holographic interferometry [8082-83]

H. H. Wahba, M. A. Shams El-Din, Univ. of Mansoura (Egypt)

8082 2C Characterization of a waveguide written by a UV laser into a planar polymer chip by digital holographic interferometry [8082-84]

M. A. Shams El-Din, H. H. Wahba, Univ. of Mansoura (Egypt); F. Vollertsen, Bremer Institut für angewandte Strahltechnik GmbH (Germany)

8082 2D Compensation of reference beam sphericity in a multi-perspective digital holography based record-display setup [8082-104]

N. Pandey, B. Hennelly, National Univ. of Ireland, Maynooth (Ireland)

$80822 \mathrm{E}$ Novel method for automatic filtering in the Fourier space applied to digital hologram reconstruction [8082-123]

O. J. Rincon, Combustion Ingenieros Ltda. (Colombia); R. Amezquita, Combustion Ingenieros Ltda. (Colombia) and Univ. Nacional de Colombia-Sede Bogota (Colombia); Y. M. Torres, V. Agudelo, Combustion Ingenieros Ltda. (Colombia)

$80822 \mathrm{~F}$ Digital holographic microscopy for dynamic imaging of hydrogels [8082-125]

C. Yuan, Univ. Stuttgart (Germany) and Kunming Univ. of Science and Technology (China); G. Pedrini, Univ. Stuttgart (Germany); G. Fu, Southeast Univ. (China); J. Ma, W. Osten, Univ. Stuttgart (Germany)

8082 2G Particle concentration effect on diffraction efficiency in two views off-axis holograms [8082-127]

L. Bouamama, S. Kara, Ferhat Abbas Univ. of Setif (Algeria); O. Chaab, S. Simoëns, Ecole Centrale de Lyon (France)

$8082 \mathrm{2H}$ Zero-order elimination in digital holography by use of two holograms: one is made by tilting the CCD [8082-151]

M. Abolhassani, Y. Rostami, Arak Univ. (Iran, Islamic Republic of)

POSTER SESSION: 3D INTERFEROMETRY AND SPECKLE TECHNIQUES

$808221 \quad$ Coherence effects in Makyoh topography [8082-88]

F. Riesz, Research Institute for Technical Physics and Materials Science (Hungary)

8082 2J Spatial phase-shift interferometry: implementation of an effective phase-recovering algorithm [8082-90]

M. Vannoni, Istituto Nazionale di Ottica Applicata, CNR (Italy); M. Melozzi, M. Barilli, Selex Galileo S.p.A. (Italy); A. Sordini, G. Molesini, Istituto Nazionale di Ottica Applicata, CNR (Italy) 
8082 2K Adaptive holographic illumination in comparative electronic speckle pattern interferometry [8082-108]

R. Séfel, J. Kornis, S. Varga-Fogarasi, Budapest Univ. of Technology and Economics (Hungary)

8082 2L Transmission sphere calibration and its current limits [8082-119]

P. Yang, Shanghai Institute of Optics and Fine Mechanics (China), and Max-Planck-Institut für Astronomie (Germany), and Graduate School of the Chinese Academy of Sciences (China); J. Xu, J. Zhu, Shanghai Institute of Optics and Fine Mechanics (China); S. Hippler, Max-Planck-Institut für Astronomie (Germany)

$80822 \mathrm{~N}$ Development of error estimation method for phase detection in phase shift method [8082-146]

R. Hanayama, The Graduate School for the Creation of New Photonics Industries (Japan);

K. Hibino, National Institute of Advanced Industrial Science and Technology (Japan)

POSTER SESSION: WHITE-LIGHT INTERFEROMETRY, OCT, AND MULTIWAVELENGTH TECHNIQUES

808220 Hybrid light source for scanning white light interferometry-based MEMS quality control [8082-107]

V. Heikkinen, K. Hanhijärvi, Univ. of Helsinki (Finland); J. Aaltonen, Helsinki Institute of Physics (Finland); H. Räikkönen, B. Wälchli, T. Paulin, Univ. of Helsinki (Finland); I. Kassamakov, Univ. of Helsinki (Finland) and Helsinki Institute of Physics (Finland); K. Grigoras, S. Franssila, Aalto Univ. School of Science and Technology (Finland); E. Haeggström, Univ. of Helsinki (Finland)

$80822 \mathrm{P}$ Development of traceability methodology for optical coherence tomography (OCT) using step height standard as calibration reference [8082-111]

I. B. Couceiro, T. Ferreira da Silva, L. V. G. Tarelho, C. L. S. Azeredo, I. Malinovski,

H. P. H. Grieneisein, W. S. Barros, INMETRO (Brazil); G. V. Faria, J. P. von der Weid, Pontificia

Univ. Católica do Rio de Janeiro (Brazil); M. M. Amaral, M. P. Raele, A. Z. de Freitas, Instituto de Pesquisas Energéticas e Nucleares (Brazil)

$80822 Q \quad$ Dispersion optimized white-light interferometer based on a Schwarzschild objective [8082-117]

P. Kühnhold, P. Lehmann, J. Niehues, Univ. of Kassel (Germany)

8082 2R Interferometric multiwavelength system for long gauge blocks measurements [8082-144] M. Wengierow, L. Sałbut, Warsaw Univ. of Technology (Poland); Z. Ramotowski, Central Office of Measures (Poland)

808225 Investigation of organic light emitting diodes for interferometric purposes [8082-160] A. Pakula, M. Zimak, L. Sałbut, Warsaw Univ. of Technology (Poland)

POSTER SESSION: POLARIZATION BASED TECHNIQUES

$80822 T \quad$ Spectral polarimetry-based measurement of the thickness of a thin film [8082-115]

P. Hlubina, J. Luńáček, D. Ciprian, Technical Univ. of Ostrava (Czech Republic) 
$80822 \mathrm{U}$ Comparative analysis of interferometric measurements of PMD on optical fibers [8082-118] T. Ferreira da Silva, J. Ferreira, G. Borghi, T. Menegotto, INMETRO (Brazil); G. Vilela de Faria, J. P. von der Weid, Pontificia Univ. Católica do Rio de Janeiro (Brazil)

$80822 \mathrm{~V}$ Determination of the characteristics of the surface of objects at optical remote sensing by the polarization-holographic imaging Stokes spectropolarimeter [8082-126]

B. Kilosanidze, G. Kakauridze, Georgian Technical Univ. (Georgia)

8082 2W Mueller matrix imaging of plasmonic polarizers on nanopatterned surface [8082-138]

L. M. S. Aas, I. S. Nerbø, M. Kildemo, Norwegian Univ. of Science and Technology (Norway);

D. Chiappe, C. Martella, F. Buatier de Mongeot, Univ. di Genova (Italy)

POSTER SESSION: TRIANGULATION AND STRUCTURED LIGHT TECHNIQUES

8082 2X Measurement of five-degrees-of-freedom error motions for a micro high-speed spindle using an optical technique [8082-95]

H. Murakami, Kyushu Sangyo Univ. (Japan)

$80822 \mathrm{Y}$ Measurement system for hot heavy forgings and its calibration [8082-105]

Y. Du, Z. Du, Shanghai Jiaotong Univ. (China)

$80822 Z$ 3D shape measurement of optical free-form surface based on fringe projection [8082-106] S. Li, S. Liu, H. Zhang, Tianjin Univ. (China)

808230 Material tests using the ARAMIS system: a laboratory report [8082-128]

C. Acevedo Pardo, J. Ohlendieck, M. Krahwinkel, H. Sternberg, HafenCity Univ. Hamburg (Germany)

808231 Calibration routine for in-process roundness measurements of steel rings during heat treatment [8082-129]

H. Gafsi, G. Goch, Univ. of Bremen (Germany)

808232 A new type of color-coded light structures for an adapted and rapid determination of point correspondences for 3D reconstruction [8082-130]

Y. Caulier, Fraunhofer Institute for Integrated Circuits (Germany); L. Bernhard, École des

Mines de Nantes (France); K. Spinnler, Fraunhofer Institute for Integrated Circuits (Germany)

808233 Positioning of scanned part inside of the laser triangulation system [8082-156]

M. Stankiewicz, J. Reiner, G. Kotnarowski, Wroclaw Univ. of Technology (Poland)

POSTER SESSION: SURFACE ROUGHNESS AND MICROSTRUCTURE MEASUREMENT

808234 Industrial surface inspection by wavelet analysis [8082-94]

T. Kreis, L. Rosenboom, W. Jüptner, Bremer Institut für angewandte Strahltechnik GmbH (Germany)

808235 Design and fabrication of White Light Confocal Microscope with funable resolution and sensitivity [8082-98]

E. Behroodi, A. Mousavian, H. Latifi, Shahid Beheshti Univ. (Iran, Islamic Republic of) 
808236 Shape and thickness measurements using a reconstruction method for linear sensor microscopy based on improvement of lateral resolution isotropy [8082-113]

M. P. Macedo, Univ. of Coimbra (Portugal) and Instituto Superior Engenharia de Coimbra (Portugal); C. M. B. A. Correia, Univ. of Coimbra (Portugal)

808238 Multiresolution analysis of angle-resolved light scattering measurements on ground surfaces [8082-124]

J. A. Böhm, Austrian Ctr. of Competence for Tribology (Austria); A. Vernes, Austrian Ctr. of Competence for Tribology (Austria) and Vienna Univ. of Technology (Austria); G. Vorlaufer, Austrian Ctr. of Competence for Tribology (Austria); M. J. Vellekoop, Vienna Univ. of Technology (Austria)

808239 New method for evaluating high-quality fog protective coatings [8082-132]

G. Czeremuszkin, M. Latreche, G. Mendoza-Suarez, Revision Military Inc. (Canada)

\section{POSTER SESSION: MEASUREMENT OF OPTICAL SYSTEMS AND ALIGNMENT}

8082 3B Dynamic concentricity measurement of large interval-diameter ratio holes with virtual annular quadrant method [8082-92]

Q. Liu, W. Yang, B. Yao, J. Jang, J. Hu, Chinese Academy of Engineering Physics (China)

$80823 \mathrm{C}$ Novel method for misalignments measurement on imaging systems through quality image analysis [8082-97]

E. Oteo, J. Fernández-Dorado, SnellOptics (Spain); J. Arasa, Technical Univ. of Catalonia (Spain); P. Blanco, SnellOptics (Spain); C. Pizarro, Technical Univ. of Catalonia (Spain)

$80823 \mathrm{D}$ Visual alignment of mechanical structures using a Bessel beam datum: practical implementation [8082-99]

D. M. Gale, Instituto Nacional de Astrofísica, Óptica y Electrónica (Mexico)

$80823 \mathrm{E}$ Choice of the reflector for the autocollimating alignment telescope [8082-100]

A. G. Anisimov, A. N. Timofeev, V. V. Korotaev, St. Petersburg State Univ. of Information Technologies, Mechanics and Optics (Russian Federation)

8082 3F Measuring the performance of visible, NIR, and LWIR optical components: a reliable, robust, high-accuracy lens measurement system [8082-139]

S. D. Fantone, D. G. Orband, Optikos Corp. (United States)

$80823 G$ The Ronchi test using a liquid crystal display as a phase grating [8082-141]

M. Mora-González, F. J. Casillas, J. Muñoz-Maciel, R. Chiu-Zarate, F. G. Peña-Lecona, Univ. de Guadalajara (Mexico)

$80823 \mathrm{H} \quad$ Software configurable optical test system for refractive optics [8082-149]

M. Z. Dominguez, L. Wang, P. Su, R. E. Parks, J. H. Burge, College of Optical Sciences, The Univ. of Arizona (United States) 
$808231 \quad H i g h$ pressure measurement by fat long period grating sensor on a single mode optical fiber [8082-93]

M. I. Zibaii, M. Kheiri, S. Nori, J. Sadeghi, H. Pourbeyram, H. Latifi, M. H. Ghezelaiagh, Shahid Beheshti Univ. (Iran, Islamic Republic of)

8082 3J Time-resolved oblique incidence interferometer for vibration analysis of rough surface [8082-120]

Y. Mizutani, T. Higuchi, T. Iwata, Univ. of Tokushima (Japan); Y. Otani, Utsunomiya Univ. (Japan)

$80823 \mathrm{~K}$ Optimized dust-proof optical fiber sensing system for real-time monitoring of frequency, phase, and vibration of rotating parts [8082-136]

K. Prokopczuk, P. Lesiak, T. Poczęsny, K. Rozwadowski, T. R. Woliński, A. W. Domański, Warsaw Univ. of Technology (Poland)

8082 3L Optical fiber macro-bend seismic sensor for real-time vibration monitoring in harsh industrial environment [8082-140]

T. Poczęsny, K. Prokopczuk, P. L. Makowski, A. W. Domański, Warsaw Univ. of Technology (Poland)

$80823 \mathrm{M} \quad$ High temperature sensing with FBGs using a tunable laser interrogation system [8082-1 42] B. Eder, M. Plattner, P. Putzer, P. Eckert, A. Reutlinger, T. Zeh, Kayser-Threde GmbH (Germany)

$80823 \mathrm{~N}$ Optical vibration measurements of cross coupling effects in capacitive micromachined ultrasonic transducer arrays [8082-147]

E. Leirset, A. Aksnes, Norwegian Univ. of Science and Technology (Norway)

\section{POSTER SESSION: DISTANCE AND DISPLACEMENT MEASUREMENT}

808230 Submicron displacements measurement by measuring autocorrelation of the transmission function of a grating [8082-135]

K. Madanipour, Amirkabir Univ. of Technology (Iran, Islamic Republic of); M. T. Tavassoly, Univ. of Tehran (Iran, Islamic Republic of)

8082 3P Optical sensor based on combined GI/DSPI technique for strain monitoring in crucial points of big engineering structures [8082-137]

D. Łukaszewski, L. Sałbut, M. Kujawińska, K. Malowany, Warsaw Univ. of Technology (Poland)

$80823 Q \quad$ Evaluation of thermal expansion coefficient of Fabry-Perot cavity using an optical frequency comb [8082-145]

J. Oulehla, R. Šmíd, Z. Buchta, M. Čížek, B. Mikel, P. Jedlička, J. Lazar, O. Číp, Institute of Scientific Instruments of the ASCR, v.v.i. (Czech Republic)

$80823 R$ Optic-electronic systems for measuring the angle deformations and line shifts of the reflecting elements at the rotateable radio-telescope [8082-150]

I. A. Konyakhin, A. N. Timofeev, A. A. Usik, D. V. Zhukov, St. Petersburg State Univ. of Information Technologies, Mechanics and Optics (Russian Federation) 
808235 Sub-ppm absolute distance measurements using an optical frequency comb generated by a conventional dual-drive Mach-Zehnder modulator [8082-153]

S. Le Floch, M. Llera, Y. Salvadé, Haute Ecole Arc Ingénierie Siège (Switzerland)

8082 3T A novel diffractive encoding principle for absolute optical encoders [8082-154]

D. Hopp, Univ. Stuttgart (Germany); D. Wibbing, Festo AG \& Co. KG (Germany); C. Pruss, W. Osten, Univ. Stuttgart (Germany); J. Binder, Festo AG \& Co. KG (Germany); W. Schinköthe, F. Sterns, Univ. Stuttgart (Germany); J. Seybold, K.-P. Fritz, V. Mayer, Hahn-SchickardGesellschaft Institut für Mikroaufbautechnik (Germany); H. Kück, Univ. Stuttgart (Germany) and Hahn-Schickard-Gesellschaft Institut für Mikroaufbautechnik (Germany)

POSTER SESSION: LASER INTERFEROMETRY AND NANO-METROLOGY

$80823 U$ AFM nanometrology interferometric system with the compensation of angle errors [8082-133]

J. Hrabina, J. Lazar, Institute of Scientific Instruments of the ASCR, v.v.i. (Czech Republic);

P. Klapetek, Czech Metrology Institute (Czech Republic); O. Cip, Institute of Scientific Instruments of the ASCR, v.v.i. (Czech Republic)

$80823 \mathrm{~V}$ Noncontact interferometric technique for calibration of coordinate measuring machines [8082-134]

A. Miks, J. Novak, P. Novak, Czech Technical Univ. in Prague (Czech Republic)

POSTER SESSION: NONDESTRUCTIVE TESTING AND PROCESS MONITORING

8082 3W Influences of colorful LED emissions on spectrophotometric properties of a LED based white light source [8082-85]

F. Sametoglu, O. Celikel, TUBITAK National Metrology Institute (Turkey)

$80823 \mathrm{X}$ Experimental study of the heat transfer process of air around atmospheric arc plasma [8082-86]

F. Salimi Meidanshahi, Shahid Beheshti Univ. (Iran, Islamic Republic of); K. Madanipour, Amirkabir Univ. of Technology (Iran, Islamic Republic of); B. Shokri, Shahid Beheshti Univ. (Iran, Islamic Republic of)

$80823 Y$ Optical characterization of three-dimensional structures within a DRAM capacitor [8082-89] M. Krupinski, Namlab GmbH (Germany); A. Kasic, aleo solar AG (Germany); T. Hecht, Evonik Litarion GmbH (Germany); M. Klude, GLOBALFOUNDRIES Inc. (Germany); J. Heitmann, Namlab GmbH (Germany) and Technical Univ. Freiberg (Germany); E. Erben, GLOBALFOUNDRIES Inc. (Germany); T. Mikolajick, Namlab GmbH (Germany) and Technische Univ. Dresden (Germany)

$80823 Z$ 3D laser scanner system based on a galvanometer scan head for high temperature applications [8082-91]

T. Hegna, H. Pettersson, K. M. Laundal, K. Grujic, Teknova AS (Norway)

808240 In-process fault detection for textile fabric production: onloom imaging [8082-103] F. Neumann, T. Holtermann, D. Schneider, RWTH Aachen (Germany); A. Kulczycki, RWTH Aachen (Germany) and Michigan State Univ. (United States); T. Gries, T. Aach, RWTH Aachen (Germany) 
808241 Fluorescence errors in integrating sphere measurements of remote phosphor type LED light sources [8082-109]

A. Keppens, Catholic Univ. College Gent (Belgium); Y. Zong, V. B. Podobedov, M. E. Nadal, National Institute of Standards and Technology (United States); P. Hanselaer, Catholic Univ. College Gent (Belgium); Y. Ohno, National Institute of Standards and Technology (United States)

808242 Optimization of measuring and calibration procedures for gas analyser based on acoustooptical tunable filters [8082-1 10]

A. V. Fadeyev, V. E. Pozhar, Scientific and Technological Ctr. for Unique Instrumentation (Russian Federation)

808243 Spectrally resolved measurement of small optical losses by cavity enhanced spectroscopy techniques [8082-116]

T. Zeuner, W. Paa, G. Schmidl, C. Mühlig, Institut für Photonische Technologien e.V. (Germany)

808244 Microlens array manufactured by inkjet printing: study of the effects of the solvent and the polymer concentration on the microstructure shape [8082-157]

I. A. Grimaldi, ENEA (Italy) and Univ. of Naples Federico II (Italy); A. De Girolamo Del Mauro, F. Loffredo, G. Nenna, F. Villani, C. Minarini, ENEA (Italy)

808245 Laser self-mixing sensor to monitor in situ the penetration depth during short pulse laser drilling of metal targets [8082-159]

F. P. Mezzapesa, CNR-IFN UOS Bari (Italy) and Politecnico di Bari (Italy); A. Ancona,

T. Sibillano, CNR-IFN UOS Bari (Italy); F. De Lucia, M. Dabbicco, P. M. Lugarà, G. Scamarcio, CNR-IFN UOS Bari (Italy) and Univ. degli Studi di Bari (Italy)

Author Index 
Downloaded From: https://www.spiedigitallibrary.org/conference-proceedings-of-spie on 26 Apr 2023

Terms of Use: https://www.spiedigitallibrary.org/terms-of-use 


\title{
Conference Committee
}

\author{
Symposium Chairs
}

Wolfgang Osten, Universität Stuttgart (Germany)

Małgorzata Kujawińska, Warsaw University of Technology (Poland)

Pietro Ferraro, Istituto Nazionale di Ottica Applicata (Italy)

Conference Chair

Peter H. Lehmann, Universität Kassel (Germany)

Conference Cochairs

Wolfgang Osten, Universität Stuttgart (Germany)

Kay Gastinger, Norwegian University of Science and Technology (Norway)

Program Committee

Astrid Aksnes, Norwegian University of Science and Technology (Norway)

Armando Albertazzi Gonçalves, Jr., Universidade Federal de Santa Catarina (Brazil)

Oleg V. Angelsky, Yuriy Fedkovych Chernivtsi National University (Ukraine)

Anand Krishna Asundi, Nanyang Technological University (Singapore)

Klaus-Friedrich Beckstette, Carl Zeiss AG (Germany)

Ralf B. Bergmann, Bremer Institut für angewandte Strahltechnik Gmbh (Germany)

Harald Bosse, Physikalisch-Technische Bundesanstalt (Germany)

Karsten Buse, Rheinische Friedrich-Wilhelms-Universität Bonn (Germany)

Yuri V. Chugui, Technological Design Institute of Scientific Instrument Engineering (Russian Federation)

Jürgen W. Czarske, Technische Universität Dresden (Germany)

Peter J. de Groot, Zygo Corporation (United States)

Cosme Furlong, Worcester Polytechnic Institute (United States)

Marc P. Georges, Université de Liège (Belgium)

Christophe Gorecki, Université de Franche-Comté (France)

Roger M. Groves, Technische Universiteit Delft (Netherlands)

Roland Höfling, ViALUX GmbH (Germany)

Pierre M. Jacquot, Ecole Polytechnique Fédérale de Lausanne (Switzerland)

Eberhard Manske, Technische Universität Ilmenau (Germany) 
Richard M. Kowarschik, Friedrich-Schiller-Universität Jena (Germany)

Małgorzata Kujawińska, Warsaw University of Technology (Poland)

Andrew J. Moore, Heriot-Watt University (United Kingdom)

Gunther Notni, Fraunhofer-Institut für Angewandte Optik und Feinmechanik (Germany)

Eduard Reithmeier, Leibniz Universität Hannover (Germany)

Robert Schmitt, Fraunhofer-Institut für Produktionstechnologie (Germany)

Jörg Seewig, Technische Universität Kaiserslautern (Germany)

Peter M. Seitz, CSEM and Swiss Federal Institute of Technology (Switzerland)

Marcus Steinbichler, Steinbichler Optotechnik GmbH (Germany)

Mitsuo Takeda, The University of Electro-Communications (Japan) 


\section{Introduction}

Industrial production processes are characterized by increasing complexity, precision, and speed. Products are becoming smaller and smarter. They comprise more functions occupying less space and thus, there is a need for more and more demanding tolerances.

Nevertheless, it still remains true, that you can only produce as accurate as you can measure. But this is not the full truth: measurement systems are required to come at least closer to industrial production lines, at best they should be integrated. Furthermore, they shall be robust and energy as well as cost efficient. Optical metrology is often the most promising approach to these diverse challenges. For these reasons optical methods are still playing an important role for measurement and testing in times of increasing requirements and advancing capabilities of production processes.

On the other hand, strong demands steadily stimulate the development of new or improved measurement methods, strategies and configurations. Novel components such as custom made light sources, light guiding and imaging systems, light modulators, and smart camera systems support research activities in the field of optical metrology. In addition, computerization enables researchers to run complex signal and image processing algorithms even in real-time applications.

Thanks to all this, the conference on Optical Measurement Systems for Industrial Inspection remains an important platform for scientific exchange and discussion of new ideas. In continuation of the Munich conference series established more than 10 years ago (see Proceedings of SPIE Vol. 3824, 4398, 5144, 5856, and 7389), this conference is a considerable event for researchers working in the field of optical metrology. Nearly 170 submissions related to the 2010 call for papers demonstrate the international recognition of the conference. With more than 150 papers in total and 80 oral presentations the 2011 conference could hold the high number and outstanding level of contributions, which made it as successful as it is today.

The layout of this proceedings volume follows the presentation order of the conference which is divided basically into general items, methodology and applications. Traditionally the methodology contributions focus on holographic, interferometric and structured light techniques. In addition, this year there are special topics on phase retrieval and fiber optic sensors, for example. General items deal with multisensor approaches, optical profilometry, and high-speed sensors. Finally, there is a broad variety of applications comprising micro- and nanostructure measurement, measurement of optical components, systems and system alignment, distance and displacement measurement, particle 
measurement, vibration measurement, nondestructive inspection and process monitoring.

All presented posters are assigned to these particular topics too. As in past conferences and again in 2011, a special session is dedicated to measurement of optical components and systems. This session will be held in cooperation with the conference on Manufacturing of Optical Components (EOSMOC 2011) organized by the European Optical Society (EOS). As a novelty the manuscripts of all contributions to this joint SPIE / EOS session will be published in this proceedings volume.

There are many people whom we would like to thank for the support of this conference. First, we would like to express our sincere gratitude to the program committee for their support in the run-up of the conference. We also thank all authors, especially the distinguished invited speakers: Pierre Slangen, Ecole des Mines d'Ales (France); Zeev Zalevsky, Bar-llan Institute of Nanotechnology \& Advanced Materials BINA (Israel); Michael Schulz, PTB (Germany); Catherine Towers, Leeds University (United Kingdom), and Yuri Chugui, Technological Design Institute of Scientific Instrument Engineering, Siberian Branch of the Russian Academy of Sciences (Russia), for their outstanding lectures on "Digital Fresnel holography and speckle interferometry;" "Advances in the field of superresolution;" "Some aspects of error Influences in interferometric measurements of optical surface forms;" "Extended range metrology;" and "3D optical measuring and laser technologies."

Finally, many thanks are also due to the SPIE staff for their excellent and cooperative work during the conference organization and the publication of these proceedings.

\section{Peter H. Lehmann Wolfgang Osten Kay Gastinger}

